[Agr. Biol. Chem., Vol. 29, No. 9, p. 824 831, 1965]

\title{
Isomerization and Racemization of Menthols
}

\author{
Part II. Isomerization and Racemization with Hydrogenation \\ Catalysts and Sodium Mentholates*
}

\author{
By Toshio Yoshida, Akira Komatsu and Motoichi Indo \\ Takasago Perfumery Co., Ltd., Tokyo \\ Received April 9, 1965
}

\begin{abstract}
The isomerization and racemization of menthol isomers have been investigated with copper chromite and Raney nickel catalyst or sodium mentholates. The equilibrium concentration has been found to correspond to $55 \sim 56 \%$ of menthol with the catalytic isomerization, whereas to $74 \sim 75 \%$ of menthol with sodium mentholates. From these data, the free energy difference between equatorial and axial group in menthols is calculated to be about $0.5 \sim 0.6 \mathrm{Kcal} . / \mathrm{mole}$ for hydroxyl and $1.4 \sim 1.5 \mathrm{Kcal} . / \mathrm{mole}$ for methyl at $200^{\circ} \mathrm{C}$.
\end{abstract}

Isomerization and racemization of alcohols have been reported by some investigators. ${ }^{1,21}$ For example, Eliel et al. $^{31}$ carried out the epimerization of many cyclohexanols and Takeshita et al." epimerized borneols with copper chromite, aluminum isopropoxide and sodium ethoxide.

Especially, the epimerization of cyclohexanols has been studied in details according to the conformational analysis with regard to stereochemical behavior. ${ }^{3,51}$

The isomerization of isomeric menthols to $(-)$-menthol and the racemization of $(+)-$ menthol series (IS) to ( \pm )-methol have been the important subjects in the industrial production of $(-)$-menthol as mentioned in the previous report. ${ }^{121}$

In 1958, Hueckel and Cheema ${ }^{61}$ reported that isomeric menthols had been isomerized with sodium in decalin at $230 \sim 240^{\circ} \mathrm{C}$ to give

\footnotetext{
* Part I. This Jounal, 27, 433 (1963).

1) W. Huekel et al., Chem. Ber., 77, 220 (1944),

2) W. E. Doering et al., J. Am. Chem. Soc., 71, 838 (1949).

3) E.L. Eliel et al., ibid, 79, 5986, 5992, 5995 (1957).

4) T. Takeshita and M. Kitajima, Bull. Chem. Soc. Japan,

$79,1468,1472,1476$ (1958).

5) E.L. Eliel et al., J. Am. Chem. Soc., 82, 1367 (1960).

6) W. Hueckel und C.Z.K. Cheema, Chem. Ber., 91, 311 (1958).
}

the menthol mixture. The composition of menthols, however, was inaccurate because an excellent method for determination of menthol isomers had not been known in these days. In 1960, the same author ${ }^{71}$ isomerized the hydrogenation product of thymol, i.e., optically inactive menthol mixture with Raney nickel in methanol at $200 \sim 250^{\circ} \mathrm{C}$ and obtained an equilibrium mixture which was composed of $57.1 \%$ menthol (I), $29.3 \%$ neomenthol (II) and 13.6\% isomenthol (III). by gas chromatography. Recently Hueckel et al. ${ }^{81}$ have studied the isomerization of menthol isomers with alcoholate in paraffin or decalin in the presence or absence of fluorenone. They have concluded that the composition of equilibrium with alcoholate at $200 \sim 230^{\circ} \mathrm{C}$. was $72 \%$ (I), 15\% (II) and 13\% (III).

On the other hand Booth ${ }^{9}$ and Bottems ${ }^{101}$ have reported the racemization of menthol by heating optically active menthol with nickel, cobalt, copper chromite or other

7) W. Hueckel et al., Ann., 637, 1 (1960).

8) W. Hueckel und E. Jordan, Arch. Pharm, 66, 563 (1961).

6) A. B. Booth, U. S. 2,843,636 (1958); C. A., 53, 3271h (1959).

10) R. R. Bottems, U. S. 2,871,272 (1958). 
hydrogenation catalysts.

Independently of other workers $s^{6 \sim 101}$ we have carried out the isomerization of isomeric menthols and presented a part of the results in 1957 and $1960 .^{111}$

This paper describes the isomerization of the isomeric menthols by heating them in the presence of hydrogenation catalysts and hydrogen in autoclave or by means of sodium mentholate. Especially, from the view of industrial production menthol was isomerizaed without solvents and the menthol composition accurately determined by gas chromatography.

In the first place, (-)-(I), (+)-(II), (+)-(III) and ( \pm )-neoisomenthol (IV) were isomerized in the presence of copper chromite catalyst (10\% weight) under the pressure of hydrogen and the results are summarized in Tables I, II and III. Although (-)-menthol has not been isomerized at a temperature below $100^{\circ} \mathrm{C}$, it has been found that at $150^{\circ} \mathrm{C}$ the isomerization occurs and at a temperature above $200^{\circ} \mathrm{C}$ any isomeric menthols furnish an equilibrium mixture. The equilibrium concentration of three isomers, (I), (II) and (III) are to $55 \sim 56 \%$ (I), $30 \sim 31 \%$ (II) and 13 14\% (III). These values are in good agreement with earlier values reported by Hueckel et al. ${ }^{7}$ Although at a temperature above $230^{\circ} \mathrm{C}$ racemization occurs as shown in Table $\mathrm{I}$ and the quantity of hydrocarbons (mainly cis- and trans-p-menthane) as well as menthone and isomenthone produced by dehydrogenation or dehydration followed by hydrogenation of starting menthols, the equilibrium composition is always constant. In the absence of hydrogen no isomerization occurred as shown in Table I as previously reported. ${ }^{10}$

Among the three isomeric menthols, neomenthol (II) was most easily isomerized and acemized to give the equilibrium mixture at it temperature above $200^{\circ} \mathrm{C}$. At $150^{\circ} \mathrm{C}(+)$ II) afforded the mixture of isomeric menthols,

11) The papers were presented at the 1st and 4th Annual Meeting of Chemistry of Perfume, Terpene and Essential Jil in Japan in Kinki and Hokkaido University, respectively. which gave a menthol, $62 \sim 63 \%$, and showed optical rotation of $\alpha_{\mathrm{D}}^{20}-19 \sim-20^{\circ}$, but at $200^{\circ} \mathrm{C}$ the racemization already occurred $\left(\alpha_{\mathrm{D}}^{20}-10 \sim-12^{\circ}\right)$. At a temperature above $230^{\circ} \mathrm{C}$ major parts of menthol were racemized and the more severe dehydration reaction occurred as shown in Table II.

In the case of $(+)$-isomenthol (III) the isomerization was somewhat difficult but also gave the same equilibrium concentration as $(-)$-(I) and (+)-(II) at $185 \sim 200^{\circ} \mathrm{C}$ as shown in Table III. Although at a temperature above $200^{\circ} \mathrm{C}$ racemization occurred, the amount of hydrocarbons by side reactions was very small in contrast with the case of $(-)-(\mathrm{I})$ or (t)-(II). Moreover, ( \pm )-neoisomenthol (IV) or the mixture composed of the equal amounts of $(-)-(\mathrm{I}),(+)-(\mathrm{II})$ and (+)-(III), was also isomerized under a hydrogen pressure of $35 \mathrm{~kg} / \mathrm{cm}^{2}$ at $200^{\circ} \mathrm{C}$ for 4.5 hours in the presence of copper chromite catalyst to afford the same equilibrium concentration mentioned above. The optical purity of isomerized menthol mixture from the optically active menthol mixture, however, was only $85.0 \%$ by the menthone enol acetate method. ${ }^{12)}$ It means that the partial racemization occurred at these conditions because the starting menthols were optically pure.

Concerning the isomerization, a copper chromite was most effective catalyst but Raney nickel was an inferior one.

Catalytic isomerization or racemization reaction was considerably inhibited by addition of ketones and in some cases even the lower alcohols such as methanol, ethanol and cyclohexanol as shown in Table IV (t)Neomenthol which could be readily converted to the equilibrium mixture, was not smoothly isomerized in the presence of (-)-menthone, $(+)$-isomenthone or cyclohexanone (even $5 \%$ amount). On the other hand these reactions were not inhibited by hydrocarbons such as $n$ hexane, cyclohexane and methylcyclohexane.

\footnotetext{
12) T. Yoshida, A. Komatsu and M. Indo, This Jounal 27, 433 (1963).
} 
TABLe I. Isomerization and RaCemization of (-)-Menthol (I) With COPPER Chromite Catalyst (10\% weight)

\begin{tabular}{|c|c|c|c|c|c|c|c|c|c|c|}
\hline \multicolumn{3}{|c|}{ Reaction } & \multirow[b]{2}{*}{$\alpha_{D}^{20}$} & \multicolumn{4}{|c|}{ Composition of Products (\%) } & \multicolumn{3}{|c|}{ Composition of Menthols (\%) } \\
\hline$\widehat{\text { Temp. }^{\circ} \mathrm{C}}$ & $\begin{array}{c}\text { Time } \\
\mathrm{hr} .\end{array}$ & $\begin{array}{c}\mathrm{H}_{2} \text {-Press } \\
\mathrm{kg} / \mathrm{cm}^{2}\end{array}$ & & $\begin{array}{l}\text { Hydro- } \\
\text { carbons }\end{array}$ & $\begin{array}{l}\text { Menth- } \\
\text { one }\end{array}$ & $\begin{array}{l}\text { Isomen- } \\
\text { thone }\end{array}$ & $\begin{array}{l}\text { Men- } \\
\text { thols }\end{array}$ & $\begin{array}{l}\text { Neomen- } \\
\text { thol }\end{array}$ & $\begin{array}{l}\text { Men- } \\
\text { thol }\end{array}$ & $\overbrace{\text { menthol }}^{\text {Iso- }}$ \\
\hline 100 & 4.5 & 35 & C.* & 0.0 & 0.0 & 0.0 & 100.0 & 0.0 & 100.0 & 0.0 \\
\hline 150 & 4.5 & 35 & -25.4 & 0.0 & 0.0 & 0.0 & 100.0 & 31.8 & 65.5 & 3.1 \\
\hline $200 * *$ & 2.0 & 15 & C.* $*$ & 0.0 & 1.6 & trace & 98.4 & 0.0 & 100.0 & 0.0 \\
\hline 200 & 2.0 & 35 & -17.4 & 1.0 & 0.0 & 0.0 & 99.0 & 31.0 & 56.2 & 12.8 \\
\hline 230 & 4.5 & 15 & -4.4 & 9.8 & 4.1 & 2.8 & 83.3 & 33.4 & 54.6 & 12.0 \\
\hline 230 & 4.5 & 70 & -12.6 & 4.0 & 0.0 & 0.0 & 96.0 & 30.7 & 55.1 & 14.2 \\
\hline 250 & 4.5 & 15 & -0.4 & 29.9 & 6.9 & 4.4 & 58.8 & 33.2 & 53.2 & 13.6 \\
\hline 250 & 9.0 & 35 & 0.0 & 16.3 & 1.7 & 1.5 & 80.5 & 31.7 & 54.2 & 14.1 \\
\hline 270 & 4.5 & 15 & 0.0 & 47.4 & 9.5 & 6.3 & 36.8 & 32.0 & 52.4 & 15.6 \\
\hline
\end{tabular}

TABLE II. ISOMERIZATION AND RACEMIZATION OF (+)-NEOMENTHOL (II) with Copper Chromite Catalyst (10\% weight)

\begin{tabular}{|c|c|c|c|c|c|c|c|c|c|c|}
\hline \multicolumn{3}{|c|}{ Reaction } & \multirow[b]{2}{*}{$\alpha_{\mathrm{D}}^{20}$} & \multicolumn{4}{|c|}{ Composition of Products (\%) } & \multicolumn{3}{|c|}{ Composition of Menthols ( $\%$ ) } \\
\hline $\begin{array}{c}\text { Temp. } \\
{ }^{\circ} \mathrm{C}\end{array}$ & $\underbrace{\text { Time }}_{\text {hr. }}$ & $\begin{array}{c}\mathrm{H}_{2} \text {-Press } \\
\mathrm{kg} / \mathrm{cm}^{2}\end{array}$ & & $\begin{array}{l}\text { Hydro- } \\
\text { carbons }\end{array}$ & $\begin{array}{c}\text { Menth- } \\
\text { one }\end{array}$ & $\begin{array}{c}\text { Isomen- } \\
\text { thone }\end{array}$ & $\begin{array}{l}\text { Men- } \\
\text { thols }\end{array}$ & $\begin{array}{l}\text { Neomen- } \\
\text { thol }\end{array}$ & $\begin{array}{l}\text { Men- } \\
\text { thol }\end{array}$ & $\overbrace{\text { menthol }}^{\text {Iso- }}$ \\
\hline 100 & 4.5 & 35 & +13.6 & 0.0 & 0.0 & 0.0 & 100.0 & 92.7 & 7.3 & 8.0 \\
\hline 130 & 4.5 & 35 & -12.2 & 0.0 & 0.0 & 0.0 & 100.0 & 47.5 & 52.5 & trace \\
\hline 150 & 4.5 & 35 & -20.8 & 0.0 & 0.0 & 0.0 & 100.0 & 30.9 & 63.6 & 5.5 \\
\hline 200 & 4.5 & 15 & -10.0 & 7.0 & 0.9 & trace & 92.1 & 31.0 & 55.6 & 13.4 \\
\hline 200 & 9.0 & 35 & -11.8 & 3.1 & trace & trace & 96.9 & 31.1 & 55.2 & 13.7 \\
\hline 230 & 4.5 & 15 & -0.2 & 20.7 & 2.8 & 1.3 & 75.2 & 29.5 & 55.9 & 14.6 \\
\hline 230 & 4.5 & 70 & -5.8 & 8.9 & 0.0 & 0.0 & 91.1 & 31.1 & 54.8 & 14.1 \\
\hline 250 & 4.5 & 35 & 0.0 & 50.0 & 1.4 & trace & 48.6 & 32.3 & 53.1 & 14.6 \\
\hline
\end{tabular}

TABLE III. ISOMERIZATION AND RACEMIZATION OF (+)-ISOMENTHOL (III) with Copper Chromite Catalyst (10\% weight)

\begin{tabular}{|c|c|c|c|c|c|c|c|c|c|c|}
\hline \multicolumn{3}{|c|}{ Reaction } & \multirow[b]{2}{*}{$\alpha_{\mathrm{D}}^{20}$} & \multicolumn{4}{|c|}{ Composition of Products (\%) } & \multicolumn{3}{|c|}{ Composition of Menthols ( $\%$ ) } \\
\hline$\widehat{\text { Temp. }}$ & Time & $\begin{array}{c}\mathrm{H}_{2} \text {-Press } \\
\mathrm{kg} / \mathrm{cm}^{2}\end{array}$ & & $\begin{array}{l}\text { Hydro- } \\
\text { carbons }\end{array}$ & $\begin{array}{c}\text { Menth- } \\
\text { one }\end{array}$ & $\begin{array}{l}\text { Isomen- } \\
\text { thone }\end{array}$ & $\begin{array}{l}\text { Men- } \\
\text { thols }\end{array}$ & $\begin{array}{l}\text { Neomen- } \\
\text { thol }\end{array}$ & $\underbrace{}_{\begin{array}{c}\text { Men- } \\
\text { thol }\end{array}}$ & $\begin{array}{l}\text { Iso- } \\
\text { menthol }\end{array}$ \\
\hline 150 & 3.0 & 10 & C.* & 0.0 & 0.0 & 0.0 & 100.0 & 15.4 & 27.2 & 57.4 \\
\hline 170 & 3.0 & 10 & -8.8 & 0.0 & 0.0 & 0.0 & 100.0 & 25.8 & 49.3 & 24.9 \\
\hline 185 & 3.0 & 10 & -14.4 & 0.0 & 1.6 & trace & 98.4 & 28.8 & 57.8 & 13.4 \\
\hline 185 & 3.0 & 35 & -14.4 & trace & 0.0 & 0.0 & 100.0 & 30.3 & 57.9 & 11.8 \\
\hline 200 & 1.0 & 10 & -12.8 & 0.0 & 1.7 & 1.1 & 97.2 & 30.4 & 55.8 & 13.8 \\
\hline 230 & 3.0 & 10 & -1.0 & 0.5 & 5.7 & 3.0 & 90.8 & 31.0 & 55.1 & 13.9 \\
\hline 250 & 2.0 & 10 & -0.2 & 4.9 & 8.6 & 6.2 & 80.3 & 32.0 & 54.4 & 13.6 \\
\hline
\end{tabular}


TABLE IV. INHIBITION OF ISOMERIZATION OF MENTHOL ISOMERS WITH Copper Chromite CATALYST (10\% weight)*

\begin{tabular}{|c|c|c|c|c|c|c|c|c|}
\hline \multirow[b]{2}{*}{$\begin{array}{l}\text { Menthol } \\
\text { Isomers }\end{array}$} & \multirow[b]{2}{*}{ Additives } & \multirow[b]{2}{*}{$\begin{array}{c}\text { Amount } \\
\%\end{array}$} & \multirow[b]{2}{*}{$\alpha_{\mathrm{D}}^{20}$} & \multicolumn{5}{|c|}{ Composition of Products $(\%)$} \\
\hline & & & & $\begin{array}{l}\text { Men- } \\
\text { thone }\end{array}$ & $\begin{array}{l}\text { Isomen- } \\
\text { thone }\end{array}$ & $\begin{array}{c}\text { Neomen- } \\
\text { thol }\end{array}$ & Menthol & $\begin{array}{c}\text { Isomen- } \\
\text { thol }\end{array}$ \\
\hline \multirow{4}{*}{ (-)-Menthol } & None & 0.0 & -24.0 & 0.0 & 0.0 & 26.3 & 67.9 & 5.8 \\
\hline & $\{(+)$-Isomenthone & 5.0 & $\mathrm{C} . * *$ & trace & trace & 5.6 & 94.4 & 0.0 \\
\hline & (-)-Menthone & 5.0 & C. *** & 1.4 & 2.2 & 2.3 & 94.1 & trace \\
\hline & None & 0.0 & -14.4 & 1.6 & trace & 28.3 & 56.9 & 13.2 \\
\hline \multirow[t]{2}{*}{$(+)$-Isomenthol } & $\{(+)$-Isomenthone & 10.0 & C. $* * *$ & 1.5 & 1.1 & 17.2 & 28.0 & 52.2 \\
\hline & (-)-Menthone & 10.0 & C. $* * *$ & 1.5 & 0.9 & 4.2 & 7.6 & 85.7 \\
\hline \multirow{10}{*}{$(+)$-Neomenthol } & None & 0.0 & -20.6 & 0.0 & 0.0 & 30.8 & 62.5 & 6.7 \\
\hline & $((+)$-Isomenthone & 5.0 & +15.2 & 0.8 & 0.8 & 90.6 & 7.8 & 0.0 \\
\hline & (-)-Menthone & 5.0 & +13.4 & 3.3 & 0.0 & 94.6 & 2.1 & 0.0 \\
\hline & Cyclohexanone & 10.0 & +14.4 & 0.0 & 0.0 & 94.7 & 5.3 & 0.0 \\
\hline & Cyclohexanol & 10.0 & +2.4 & 0.0 & 0.0 & 74.8 & 25.2 & 0.0 \\
\hline & Methanol & 10.0 & -3.2 & 0.0 & 0.0 & 62.9 & 34.5 & 2.6 \\
\hline & Ethanol & 10.0 & +13.4 & 0.7 & 0.0 & 90.5 & 8.8 & trace \\
\hline & $n$-Hexane & 10.0 & -20.8 & 0.0 & 0.0 & 33.0 & 62.0 & 5.0 \\
\hline & Cyclohexane & 10.0 & -16.8 & 0.0 & 0.0 & 41.2 & 56.0 & 2.8 \\
\hline & Methylcyclohexane & 10.0 & -16.8 & 0.0 & 0.0 & 40.8 & 55.7 & 3.5 \\
\hline
\end{tabular}

* Hydrogen pressure, $10 \mathrm{~kg} / \mathrm{cm}^{2}$; Reaction time and temperature, $2 \mathrm{hrs}$. and $150^{\circ} \mathrm{C}$ in the case of $(-) \cdot$ menthol and $(+)$-neomenthol, $3 \mathrm{hrs}$, and $185^{\circ} \mathrm{C}$ in the case of $(t)$-isomenthol

** Crystals

TABLE V. ISOMERIZATION AND RACEMIZATION OF MENTHOL ISOMERS WITH RANEY Nickel (W-4) Catalyst (10\% weight)

\begin{tabular}{|c|c|c|c|c|c|c|c|c|c|}
\hline \multirow[b]{2}{*}{$\begin{array}{l}\text { Menthol } \\
\text { Isomers }\end{array}$} & \multirow[b]{2}{*}{$\underset{{ }^{\circ} \mathrm{C}}{\text { Temp. }}$} & \multirow[b]{2}{*}{$\alpha_{\mathrm{D}}^{20}$} & \multicolumn{4}{|c|}{ Composition of Products $(\%)$} & \multicolumn{3}{|c|}{ Composition of Menthols ( $\%$ ) } \\
\hline & & & $\begin{array}{l}\text { Hydro- } \\
\text { carbons }\end{array}$ & $\begin{array}{l}\text { Menth- } \\
\text { one }\end{array}$ & $\begin{array}{l}\text { Isomen- } \\
\text { thone }\end{array}$ & $\begin{array}{l}\text { Men- } \\
\text { thols }\end{array}$ & $\begin{array}{l}\text { Neomen- } \\
\text { thol }\end{array}$ & $\begin{array}{l}\text { Men- } \\
\text { thol }\end{array}$ & $\begin{array}{c}\text { Isomen- } \\
\text { thol }\end{array}$ \\
\hline \multirow{3}{*}{ (-)-Menthol } & 180 & -15.8 & 0.0 & 0.0 & 0.0 & 100.0 & 33.2 & 66.8 & 0.0 \\
\hline & 200 & -7.6 & 0.6 & 0.0 & 0.0 & 99.4 & 29.7 & 58.5 & 11.8 \\
\hline & 230 & 0.0 & 5.8 & 2.3 & 1.5 & 90.4 & 31.5 & 55.4 & 13.1 \\
\hline \multirow{4}{*}{$(t)$-Neomenthol } & 150 & -18.4 & 0.0 & 0.0 & 0.0 & 100.0 & 40.0 & 60.0 & 0.0 \\
\hline & 180 & -18.6 & 0.0 & 0.0 & 0.0 & 100.0 & 30.8 & 61.1 & 8.1 \\
\hline & 200 & -9.0 & 0.0 & 1.3 & 0.0 & 98.7 & 30.4 & 57.8 & 11.8 \\
\hline & 230 & 0.0 & 2.0 & 1.7 & 1.0 & 95.3 & 33.5 & 55.2 & 11.3 \\
\hline \multirow{3}{*}{ (+)-Isomenthol } & 180 & -8.0 & 0.0 & 0.0 & 0.0 & 100.0 & 28.4 & 55.1 & 16.5 \\
\hline & 200 & -7.6 & trace & trace & trace & 100.0 & 27.7 & 55.5 & 16.8 \\
\hline & 230 & 0.0 & 4.7 & trace & trace & 95.3 & 30.5 & 54.6 & 14.9 \\
\hline
\end{tabular}

* Reaction time $3 \mathrm{hrs}$., hydrogen pressure $35 \mathrm{~kg} / \mathrm{cm}^{2}$

It seems reasonable that at a catalyst surface $\pi$-electrons or lone-pair electrons belonging to these ketones or alcohols will fill the vacant $d$-orbitals of catalyst metals, namely active center, and act as a kind of catalyst poison.

The results by means of Raney nickel catalyst are summarized in Table V. At $150 \sim 180^{\circ} \mathrm{C}(+)-(\mathrm{II})$ is isomerized to give a mixture, of which menthol (I) content is $60 \sim 61 \%$ and at $230^{\circ} \mathrm{C}$ it affords the same equilibrium mixture mentioned above, being completely racemized.

By this catalyst, (+)-(III) is similarly equili- 
brated at $180 \sim 200^{\circ} \mathrm{C}$ but shows a tendency of racemization to some extent. At $230^{\circ} \mathrm{C}$ $(+)-(I I I)$ as well as $(-)-(\mathrm{I})$ are sufficiently racemized.

It was shown that Raney nickel catalyst has an excellent racemization ability and produces very small quantity of by-products such as $p$-menthanes.

The isomerization by means of sodium mentholate was also investigated. After (+)(II) had been converted to sodium mentholate by adding sodium metal ( 0.8 mole equivalent), the mentholate mixture was heated at 190 $210^{\circ} \mathrm{C}$ for 12 hours to afford an equilibrium mixture. The final composition was $8 \sim 9 \%$ (-)-menthone and (+)-isomenthone, $67 \sim 68 \%$ $(-)-(\mathrm{I}), 8 \sim 9 \%(+)-(\mathrm{II})$ and $15 \sim 16 \%(+)-(\mathrm{III})$. It is known that the equilibrium menthol mixture contains $74 \sim 75 \%$ of $(-)-(\mathrm{I})$ which corresponds to much more (-)-(I) than by means of hydrogen catalysts.

Moreover, as a result of these experiments it became clear that all isomeric menthols of an equilibrium mixture with mentholates were optically pure, in other words no racemization reaction occurred and ketones such as menthone or isomenthone showed no inhibitory action.

Although (-)-(I), especially (+)-(III), was hardly isomerized with the corresponding sodium mentholate, these crystalline menthols, (I) and (III), were readily isomerized to give an equilibrium mixture in the presence of menthone or neomenthol (about 30 50\% amount for them). Moreover, the menthol mixture composed of equal amounts of isomers afforded the same equilibrium mixture.

The mechanism of isomerization is not clear but the enolization of menthones formed through these conditions might be fairly important. Menthone and isomenthone are invariably formed in the equilibrium mixture with both hydrogen catalysts and mentholates.

In the case of catalytic isomerization the equilibrium concentration of the three isomers is $56 \%$ (I), $31 \%$ (II) and $13 \%$ (III) and cor- responds to $64.4 \%$ (I) and $35.6 \%$ (II), giving an equilibrium constant $(K)$ of $31 / 56$ and a free energy difference $(\Delta F=-R T \ln R)$ of $0.56 \mathrm{Kcal} . / \mathrm{mole}$ at $200^{\circ} \mathrm{C}$. Similarly, the above equilibrium data give a free energy difference between menthol and isomenthol of $1.4 \sim 1.5 \mathrm{Kcal} . / \mathrm{mole}$.

Each menthol isomer should exist as the two conformational pairs in the stable and chair form as shown in Fig. 1. If the one of the two conformers, in which the most bulky isopropyl group occupies an equatorial (e) position, i.e., (Ia), (IIa) or (IIIa), is a preferred conformation as reported by Cole and Jefferies, ${ }^{13)}$ a free energy difference $(0.5 \sim 0.6$ or $1.4 \sim 1.5 \mathrm{Kcal} . / \mathrm{mole}$ ) between menthol (Ia) and neomenthol (IIa) or isomenthol (IIIa) would correspond to $e-\mathrm{OH} \rightarrow a-\mathrm{OH}$ or $e-\mathrm{CH}_{3} \rightarrow a$ $\mathrm{CH}_{3}$. The $\Delta F$ between equatorial and axial hydroxyl is in fair agreement with earlier values of $0.8^{141} 0.9^{151}$ and $0.5^{31} \mathrm{Kcal} . / \mathrm{mole}$ reported in cyclohexanols, and the $\Delta F$ between equatorial and axial methyl is in good agreement with the reported values of $1.49 \sim$ $1.61^{16,17)}$ in dimethylcyclohexanes; $1.5 \pm 0.1^{51}$ and $1.8 \mathrm{Kcal} . / \mathrm{mole}^{14)}$ in methylcyclohexanols.

Although the composition of neoisomenthol (IV) was not determined, $\Delta F$ between menthol (Ia) and neoisomenthol (IVa) is theoretically calculated as about $2.0 \mathrm{Kcal}$./mole $\left(e-\mathrm{CH}_{3}, e-\mathrm{OH} \rightarrow a-\mathrm{CH}_{3}, a-\mathrm{OH}\right)$. Consequently, the theoretical equilibrium concentration of four menthol isomers should be $53.5 \%$ (I), $28.3 \%$ (II), $12.1 \%$ (III) and $6.1 \%$ (IV). The precise determination of (IV) under the best conditions of gas chromatography afforded the values of $51.9 \%$ (I), 30.9\% (II), $12.5 \%$ (III) and $4.7 \%$ (IV) in an equilibrium mixture. These values are in good agreement with the calculated ones.

13) A. R. H. Cole and P.R. Jefferies, J. Chem. Soc., 4391 (1956).

14) S. Winstein and N. J. Holness, J. Am. Chem. Soc., 77, 5562 (1955).

15) S. J. Angyal and D. J. Mchugh, Chem. \& Ind., 1147 (1956).

16) J. E. Kilpatrick et al., C. A., 42, $2504^{\circ} \mathrm{C}$ (1948).

17) B. J. Armitage et al., Tetrahedron, 20, 747 (1964). 


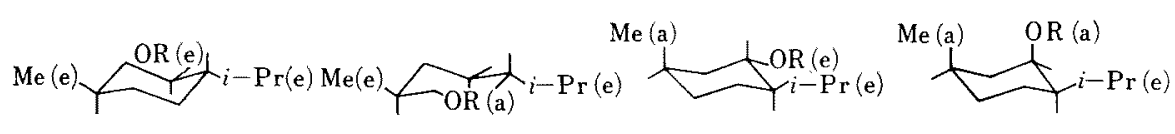

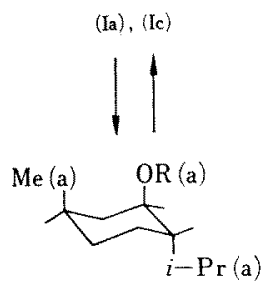

(Ib), (Id)

Menthol (I)
(II a), (II c)
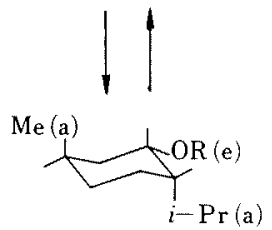

(II b) , (II d)
(IIIa), (IIl c)
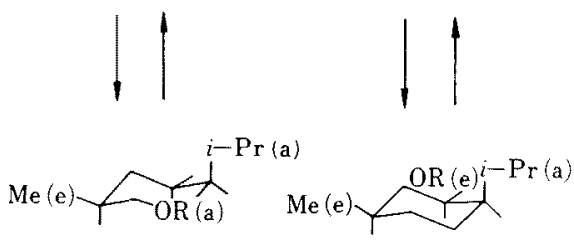

(II b), (llld)
(Nb), (N d)

Neomenthol (II) Isomenthol (III)

Neoisomenthol (IV)

Fig. 1. The Conformations of Isomeric Menthols.

$$
\text { a), b) } \mathrm{R}=\mathrm{H} \text {; c), d) } \mathrm{R}=\mathrm{Na}
$$

In the catalytic isomerization mentioned above the species equilibrated are the free alcohols, whereas in the isomerization with sodium mentholate the species equilibrated are alcoholates. The bulky alkoxide group will have a strong tendency to occupy the equatorial position so that the conformers are entirely in forms (Ic), (IId), (IIIc) and (IVd) as suggested by Eliel et al. ${ }^{5,18}$ Accordingly, the energy difference between their isomers should be equal to that of between equatorial and axial methyl or isopropyl group.

For the methyl group the free energy difference between $e$ - and $a$-methyl at $200^{\circ} \mathrm{C}$ is $1.4 \sim 1.5 \mathrm{Kcal} . / \mathrm{mole}$ as already mentioned above. The $\Delta F$ value for isopropyl group is reported previously as about 3.3 at $25 \sim 50^{\circ} \mathrm{C}^{14 \text { ! }}$ or $3.5 \mathrm{Kcal} . / \mathrm{mole}$ at $100^{\circ} \mathrm{C}^{191}$ From these data, the equilibrium concentration of sodium mentholates is calculated to be about $79.2 \%$ (I), $0.6 \%$ (II), $17.8 \%$ (III) and $2.4 \%$ (IV). Although the calculated value is in fairely good agreement with the observed one (74 $75 \%$ (I), 8〜9\% (II), 16 17\% (III)), the agreement is not so good for neomenthol (II).

The discrepancy may possibly be due to

18) E.L. Eliel, Experientia, 9, 91 (1953).

19) D.S. Noyce and L.S. Dolby, J. Org. Chem., 26, 3619 (1961). the presence of unreacted free neomenthol in the equilibrium mentholate mixture because the available amount of sodium had to be restricted to 0.8 equivalent for menthol in order to avoid the solidification of reaction mixture.

By precise gas chromatographic analysis it was possible to detect very small quantities (about $1 \%$ ) of neoisomenthol in an equilibrium mixture with sodium mentholates. This value is also in excellent agreement with the calculated one.

\section{SUMMARY}

1) The catalytic isomerization and racemization of menthol isomers by means of copper chromite and Raney nickel catalyst were investigated.

2) Although Raney nickel catalyst was excellent in the racemization ability, copper chromite had be better used as the isomerization catalyst.

3) In the case of catalytic isomerization and racemization the ketones, especially menthone and isomenthone, showed considerable inhibitory action.

4) The equilibrium concentration in the catalytic isomerization corresponded to 52 $53 \%$ menthol, $30 \sim 31 \%$ neomenthol, $12 \sim 13 \%$ 
isomenthol and $4 \sim 5 \%$ neoisomenthol at $200^{\circ} \mathrm{C}$.

5) The isomerization of menthols by means of sodium mentholates was also studied. It was shown that the equilibrium menthol mixture was composed of $74 \sim 75 \%$ menthol, 8 9\% neomenthol, $16 \sim 17 \%$ isomenthol and trace of neoisomenthol without any racemization.

6) From these data a free energy difference between equatorial and axial hydroxyl (or methyl) in menthols is calculated to be $0.5 \sim 0.6 \mathrm{Kcal} . / \mathrm{mole}$ for hydroxyl and 1.4 1.5 $\mathrm{Kcal} . /$ mole for methyl at $200^{\circ} \mathrm{C}$.

\section{EXPERIMENTAL}

\section{Materials}

(-)-Menthol. It was commercial preparation and showed the following constants; m.p. $41 \sim 42^{\circ} \mathrm{C}$, $[\alpha]_{\mathrm{D}}^{20}=-50.0$ (c=10, in ethanol).

$(+)$-Neomenthol. The crude neomenthol (500 g) containing about $78 \%$ of neomenthol, which was obtained as by-product in our company in the synthesis of (-)-menthol, acetic anhydride $(500 \mathrm{~g})$ and anhydrous sodium acetate $(50 \mathrm{~g})$ were refluxed for 16 hrs. at $140 \sim 150^{\circ} \mathrm{C}$. After cooling, water $(500 \mathrm{ml})$ was added and the mixture stirred for $1 \mathrm{hr}$. at $60^{\circ} \mathrm{C}$ in order to decompose excess of acetic anhydride. The oily layer was separated, washed with water thoroughly, dried and distilled through a $800 \times 15 \mathrm{~mm}$ column packed with Helipac at reflux ratio of $8: 1$ to give an oil, b.p. $75 \sim 77^{\circ} \mathrm{C} / 2.5 \mathrm{~mm}$. Yield $506 \mathrm{~g}$. The oil was kept overnight at $-10^{\circ} \mathrm{C}$ to afford $340 \mathrm{~g}$ of crystals. Recrystallization from $n$-hexane $(70 \mathrm{ml})$ gave pure $(+)$-neomenthyl acetate $(255 \mathrm{~g})$, m.p. $35 \sim 36^{\circ} \mathrm{C}$. The pure acetate in methanol $(360 \mathrm{ml})$ was saponified with $50 \%$ aqueous sodium hydroxide $(220 \mathrm{~g})$ under reflux for $7 \sim 8$ hrs. After methanol was recovered and water was added, the oily layer was extracted with ether, washed with water, dried and distilled through a Widmer column $(15 \mathrm{~cm})$ to give pure (t)-neomenthol (181 g), b.p. $64 \sim 66^{\circ} \mathrm{C} /$ $2.5 \mathrm{~mm}, \quad n_{\mathrm{D}}^{20}=1.4615, \quad d_{4}^{20}=0.9002, \quad \alpha_{\mathrm{D}}^{20}=+16.8$ (homog.), $p$-nitrobenzoate, m.p. $95^{\circ} \mathrm{C}$ (Lit.20) $95^{\circ} \mathrm{C}$ ). (t)-Isomenthol. The crude $(+)$-isomenthol (about $80 \%$ content, $690 \mathrm{~g}$ ) (one of the by-products in menthol synthesis) was recrystallized from nitromethane (two-fold weight for isomenthol) several times to give pure $(+)$-isomenthol $(343 \mathrm{~g})$, m.p. $82 \sim 83^{\circ} \mathrm{C}$ (Lit. ${ }^{20)}$ 20) J. L. Simonsen, "The Terpenes," Vol. 1, Cambridge at the University Press, 1947, p. 243. $\left.82 \sim 83^{\circ} \mathrm{C}\right),[\alpha]_{D}^{20}=+27.1(c=10$, in ethanol), $p$-nitrobenzoate, m.p. $53 \sim 54^{\circ} \mathrm{C}$ (Lit. 20$) 54^{\circ} \mathrm{C}$ ).

(士)-Neoisomenthol. Thymol $(20 \mathrm{~g})$ in ethanol $(40 \mathrm{ml})$ was hydrogenated in the presence of Raney nickel $\mathrm{W}-4$ (about $3 \mathrm{~g}$ ) at $150^{\circ} \mathrm{C}$ for $8 \mathrm{hrs}$. while the pressure of hydrogen kept constant at $20 \mathrm{~kg} / \mathrm{cm}^{2}$ in order to prevent the isomerization of neoismenthol formed. The hydrogenated product was filtered and the solvent was recoverd. The residual oil $(20.5 \mathrm{~g})$ was composed of menthone $2.6 \%$, isomenthone $10.9 \%$, neomenthol $4.3 \%$, neoisomenthol $52.6 \%$, menthol trace and isomenthol $19.6 \%$. Then the oil $(75 \mathrm{~g})$ was fractionally distilled at reflux ratio of $40: 1$ through the same column packed with Helipac to give crude $( \pm)$-neoisomenthol $(34.8 \mathrm{~g})$, b.p. $\sim 70^{\circ} \mathrm{C}$ $1 \sim 2 \mathrm{~mm}$ (menthone $2.3 \%$, isomenthone $8.9 \%$, neomenthol 21.4\% neoisomenthol 67.4\%). To this crude neoisomenthol (34 g) in pyridine $(90 \mathrm{ml})$ 3,5-dinitrobenzoyl chloride $(34 \mathrm{~g})$ was added in a small portion with stirring below $30^{\circ} \mathrm{C}$ and the mixture was stirred for $4.5 \mathrm{hrs}$. at room temperature. Then the reaction mixture was poured into water, extracted with ether, washed with water, $10 \%$ sulfuric acid and water successively. The ether was distilled off and residual oil steam distilled togive the distillate and the residue ( $p$-nitrobenzoates). The residue was dissolved in ether, washed with $5 \%$ sodium carbonate and then water, removal of ether gave crude ester $(43.8 \mathrm{~g})$. Since an attempt to purify this crude ester by recrystallization from methanol was unsuccessful, the impure crystals $\left(35 \mathrm{~g}\right.$ ), m.p. $76 \sim 79^{\circ} \mathrm{C}$ (Lit. $\left.{ }^{20}\right) 73^{\circ} \mathrm{C}$ ), after once recrystallization, were hydrolyzed with methanolic potassium hydroxide to give impure $( \pm)$ neoisomenthol, b.p. $72 \sim 73^{\circ} \mathrm{C} / 3.5 \mathrm{~mm}, \quad n_{\mathrm{D}}^{20}=1.4661$, $d_{4}^{20}=0.9098, \quad \alpha_{\mathrm{D}}^{20} \pm 0.0, \quad$ which was composed of neomenthol $19.1 \%$, neoisomenthol $78.5 \%$ and isomenthol $2.4 \%$.

$(-)$-Menthone and (+)-Isomenthone. They were obtained by chromic acid oxidation of $(-)$-menthol or (+)-isomenthol in the usual way, ${ }^{211}$

The other compounds in this experiment were purchased from commercial sources and used without further purification.

\section{General Procedure for Catalytic Isomerization and Racemization}

Menthol isomers $(1.5 \sim 10.0 \mathrm{~g})$ and commercial copper chromite catalyst (Nikko Co., Ltd,, Tokyo, Japan) (10\% weight for menthol isomers) or Raney nickel catalyst W-4 (stored in ethanol, $10 \%$ weight

21) Org. Synth., Coll., Vol. I, 340 (1961). 
for menthols) was placed in an autoclave $(100 \mathrm{ml})$ under hydrogen atomosphere $\left(10 \sim 70 \mathrm{~kg} / \mathrm{cm}^{2}\right)$ and agitated electrically at a given temperature for several hours. In the case of Raney nickel catalyst, $n$-hexane (the same amount for menthols) was added as a solvent and the catalyst was sufficiently washed with the same solvent to remove ethanol previously. After the reaction, the catalyst was filtered off. The results are summarized in Tables I, II, III and V.

In the experiments of inhibitory action, (-)-menthone, (t)-isomenthone, cyclohexanone, $n$-hexane, cyclohexane, methylcyclohexane, cyclohexanol, methanol or ethanol in a given amount was added together with menthols and treated as described above. The results are shown in Table IV.

\section{Isomerization of $(+)$-Neomenthol by Means of Sodium Mentholate}

To $(+)$-neomenthol $(20 \mathrm{~g})$ heated at $120 \sim 130^{\circ} \mathrm{C}$ was portionwise added sodium metal $(2.4 \mathrm{~g}, 0.8$ mole equivalent) with vigorous stirring. After the addition the mixture was kept at this temperature for $2 \mathrm{hrs}$. until the major parts of sodium disapeared. Then the temperature was gradually raised to $190 \sim 210^{\circ} \mathrm{C}$ and the mixture was stirred for 12 hrs. at this temperature. After the temperature was kept below at $140 \sim 150^{\circ} \mathrm{C}$, water (about $50 \mathrm{ml}$ ) was dropwise added. The mixture was refluxed for $30 \mathrm{~min}$. and extracted with ether. The extract was washed with water, dried and evaporated to give an isomerized oil quantitatively. The oil was composed of menthone $4 \sim 6 \%$, isomenthone $3 \sim 4 \%$, menthol $67 \sim 68 \%$, neomenthol $8 \sim 9 \%$ and isomenthol $15 \sim 16 \%$.

Although (-)-menthol or $(+)$-isomenthol was treated similarly, the isomerizaton was very difficult or impossible owing to that the corresponding mentho- lates have a strong tendency to solidify. Upon addition of $30 \sim 50 \%$ menthone or neomenthol the reaction smoothly proceeded.

\section{The Determination of Optical Purity}

Optical purity of menthol mixture was determined by the menthone enol acetate method reported in the preceeding paper by the authors. ${ }^{12}$ )

A) The optical purity of an equilibrium menthol mixture, which was obtained from optically pure (-)-menthol with copper chromite catalyst at $200^{\circ} \mathrm{C}$ for $3 \mathrm{hrs}$. under hydrogen pressure $\left(35 \mathrm{~kg} / \mathrm{cm}^{2}\right)$, corresponded to $84.9 \%$.

B) The racemization mixture which was obtained from optically pure $(-)$-menthol, $(+)$-neomenthol or $(+)$-isomenthol in $n$-hexane with Raney nickel W-4 under hydrogen pressure $\left(35 \mathrm{~kg} / \mathrm{cm}^{2}\right)$ for $3 \mathrm{hrs}$, at $230^{\circ} \mathrm{C}$, was completely optically inactive.

C) An equilibrium mixture by means of sodium mentholate from (+)-neomenthol (optical purity $96.2 \%$ ) under the conditions mentioned above showed no racemization (optical purity $96.5 \%$ ).

\section{Gas Chromatography}

The standard Kotaki Super Fractioner equipped with thermal conductivity detector was used. The samples were introduced through a $200 \times 0.32 \mathrm{~cm}$ i.d. stainless steel column packed with 20 wt. $\%$ LAC-2R446 (Cambridge Industries Co., Inc. Cambridge, Mass.) on celite $545\left(50 \sim 80 \mathrm{mesh}\right.$ ) at $140^{\circ} \mathrm{C}$ (or $120^{\circ} \mathrm{C}$ for the determination of neoisomenthol), $45 \mathrm{ml} / \mathrm{min}$. of helium as carrier gas. The retention times for menthones and menthols at $140^{\circ} \mathrm{C}$ (or $120^{\circ} \mathrm{C}$ ) were as follows: menthone $10.5(13.9)$, isomenthone 12.0 (16.2), neomenthol 14.0 (19.8), neoisomenthol 16.2 (23.5), menthol $17.5(25.6)$ and isomenthol $19.4 \mathrm{~min}$. (28.4 min.). 